\title{
Effect of caffeine on biomarkers of oxidative stress in lenses of rats with streptozotocin-induced diabetes
}

Ilona Kaczmarczyk-Sedlak ${ }^{1}$, Joanna Folwarczna ${ }^{2}$, Lech Sedlak ${ }^{3,4}$, Maria Zych $^{1}$, Weronika Wojnar ${ }^{1}$, Iwona Szumińska1 ${ }^{1}$, Dorota Wyględowska-Promieńska ${ }^{3,4}$, Ewa Mrukwa-Kominek ${ }^{3,4}$

${ }^{1}$ Department of Pharmacognosy and Phytochemistry, School of Pharmacy with the Division of Laboratory Medicine in Sosnowiec, Medical University of Silesia in Katowice, Poland

2Department of Pharmacology, School of Pharmacy with the Division of Laboratory Medicine in Sosnowiec, Medical University of Silesia in Katowice, Poland ${ }^{3}$ Department of Ophthalmology, University Clinical Center, Medical University of Silesia in Katowice, Poland

${ }^{4}$ Department of Ophthalmology, School of Medicine in Katowice, Medical University of Silesia in Katowice, Poland

Submitted: 7 February 2017

Accepted: 4 May 2017

Arch Med Sci 2019; 15 (4): 1073-1080

DOI: https://doi.org/10.5114/aoms.2019.85461

Copyright @ 2019 Termedia \& Banach

\section{Abstract}

Introduction: One of the major causes of cataract in diabetes is oxidative stress induced by reactive oxygen species (ROS). Nowadays, new substances with antioxidative properties that may prevent cataract development are needed. One such substance is caffeine - an alkaloid with well-documented antioxidative activity.

Material and methods: The study was conducted on lenses obtained from female rats, divided into 3 groups: control rats; diabetic rats; diabetic rats treated with caffeine at a dose of $20 \mathrm{mg} / \mathrm{kg}$ p.o. Type 1 diabetes was induced by streptozotocin $(60 \mathrm{mg} / \mathrm{kg}$ i.p.). After 4 weeks of caffeine administration, the rats were sacrificed, and the lenses were collected, weighed and homogenized in PBS. The homogenate was used for analysis of protein content, glutathione (GSH) concentration, advanced oxidation protein product (AOPP) concentration, malondialdehyde (MDA) concentration and the activity of superoxide dismutase (SOD), catalase (CAT) and glutathione peroxidase (GPx).

Results: The SOD, CAT and GPx activities were found to be higher in the lenses of diabetic rats. There were also increased MDA and AOPP concentrations as well as decreased GSH concentration. The administration of caffeine resulted in decreased activity of SOD, CAT and GPx. The treatment with caffeine also caused an increase of GSH concentration and a decrease of MDA and AOPP concentrations.

Conclusions: The results of the present study may be of relevance in determining the effect of caffeine on the processes induced by ROS in vivo. Further, they can be an indication for clinical observations aiming at the assessment of both preventive and therapeutic effects of caffeine in cataract.

Key words: diabetes, oxidative stress, rats, caffeine, streptozotocin, lenses.

\section{Introduction}

The main ocular complications associated with diabetes mellitus are cataract, diabetic retinopathy, glaucoma, and ocular surface diseases. In-

\author{
Corresponding author: \\ Lech Sedlak MD \\ Department \\ of Ophthalmology \\ School of Medicine \\ Medical University \\ of Silesia \\ 35 Ceglana St \\ 40-514 Katowice, Poland \\ Phone: +48 504819778 \\ E-mail: lech.sedlak@gmail. \\ com
}


creased reactive oxygen species (ROS) production and development of oxidative stress in ocular tissues play an important role in the pathogenesis of these complications [1]. Reactive oxygen species lead to oxidation, crosslinking and aggregation of lens proteins, peroxidation of membrane lipids, and apoptosis of the lens epithelial cells [2, 3]. In the lens, the toxic effects of ROS are neutralized by antioxidants such as ascorbic acid, vitamin E, glutathione, as well the enzymes glutathione peroxidase, superoxide dismutase and catalase [4-6].

Several studies have suggested that the intake of antioxidants may slow the progression of cataract $[5,6]$. Therefore, new strong antioxidants, which may become helpful in the therapy and prevention of cataract, are being sought. One candidate compound with antioxidant activity may be caffeine.

Caffeine (1,3,7-trimethylxanthine) is an alkaloid that is present in many plants, including coffee beans (Coffea arabica and Coffea robusta), cola nuts (Cola acuminata), tea leaves (Camellia sinensis), yerba mate leaves (llex paraguariensis), cocoa beans (Theobroma cacao) and guarana berries (Paullinia cupana). Caffeine is one of the ingredients of chocolate. It is present in many beverages such as coffee, tea, cocoa and cola drinks. Caffeine is the most frequently consumed psychostimulant, with approximately $80 \%$ of the population consuming it daily [7].

Caffeine has been reported as a protective substance against cellular damage with beneficial antioxidant effects [8-10]. Intake of caffeine is associated with reduced levels of biomarkers of oxidative stress [11-15]. Caffeine is able to scavenge ROS, particularly the hydroxyl radical, known to be generated in the body by exposure to $\mathrm{ul}$ traviolet light and by many physiologic reactions involving oxygen utilization $[16,17]$. Additionally, caffeine has been shown to prevent Fenton's reaction-induced oxidation of glutathione (GSH) [17], a major antioxidant reserve in many tissues, including the lens. The level of inhibition of lipid peroxidation by caffeine is the strongest, medium, and the weakest with regard to hydroxyl radical, singlet oxygen and peroxyl radical, respectively. It has been suggested that the antioxidative properties of caffeine are comparable to GSH and significantly higher than those of ascorbic acid [16]. Caffeine acts as an antioxidant in different organs also through increasing the concentration and activity of antioxidant enzymes [18, 19].

At moderate doses, caffeine acts as a competitive antagonist at the $A_{1}$ and $A_{2 A}$ adenosine receptors, which are $G$ protein-coupled receptors widely distributed throughout the body, including brain, heart, vessels and kidneys. At high doses, this alkaloid acts as a phosphodiesterase inhibi- tor, which results in intracellular cAMP accumulation and intensified sympathetic nervous system activation. It also sensitizes dopamine receptors, increases the intracellular calcium concentration and induces noradrenaline release in the central nervous system [20].

Caffeine has been shown to have several physiologic effects such as a general metabolic [21-23] and thermogenesis [24] stimulation. It was also used as a nervous system, respiratory and cardiac stimulant, smooth muscle relaxant and as a diuretic [25].

Caffeine intake has been associated with protection against diabetes mellitus, cardiovascular disease, Parkinson's disease, and Alzheimer's disease $[26,27]$. A new interest in caffeine in ophthalmology emerged with the observation that caffeine inhibits cataractogenesis [28-31]. For example, there have been reports describing the reduction of the severity of cataract due to the administration of caffeine in rats in which the lens opacity was induced by galactose [14], and in vitro in lenses exposed to ultraviolet light at a wavelength of $302 \mathrm{~nm}$ [15].

The aim of this study was to investigate the influence of caffeine on reactive stress biomarkers in lenses of rats with experimental type 1 diabetes, in comparison with a control group of healthy individuals. The standard model of type 1 diabetes induced by streptozotocin was used [32, 33]. The effect of caffeine on reactive stress biomarkers was assessed based on superoxide dismutase (SOD), catalase (CAT) and glutathione peroxidase (GPx) activities, glutathione (GSH) concentration, the level of advanced oxidation protein products (AOPP) and the concentration of a product of lipid peroxidation - malondialdehyde (MDA). Additionally, the influence of caffeine on selected oxidative stress parameters in the blood serum of these animals was evaluated.

\section{Material and methods}

\section{Animals, diabetes induction and administration of caffeine}

The biological material used in the study was obtained during the experiments performed in the Department of Pharmacology, School of Pharmacy with the Division of Laboratory Medicine in Sosnowiec $[34,35]$. The experiments were conducted with the approval of the Local Ethics Commission in Katowice (approval no. 81/2013, 40/2014, 41/2014).

Briefly, the study was carried out on sexually mature female Wistar rats, provided by the Centre of Experimental Medicine at the Medical University of Silesia. During the whole experiment, the rats were fed with standard laboratory chow and 
had unlimited water supply. The glucose concentrations in blood samples taken from tail vessels were measured with an Accu-Chek Performa glucometer (Roche Diagnostics; upper limit of detection $-600 \mathrm{mg} / 100 \mathrm{ml}$ ) [35]. Type 1 diabetes was induced by a single intraperitoneal (i.p.) administration of streptozotocin (Cayman Chemical Company) at a dose of $60 \mathrm{mg} / \mathrm{kg}$ dissolved in citrate buffer $\mathrm{pH} 4.5$ (groups D and D + C) [35]. Only the rats in which diabetes developed were included in the experiment. The baseline values of the body mass and blood glucose levels are presented in Table I.

The biological material used in the present study was collected from the animals of the following groups: ND - control, non-diabetic rats $(n=9)$; D - diabetic rats $(n=7) ; \mathrm{D}+\mathrm{C}$ - diabetic rats receiving caffeine (Sigma-Aldrich) at a dose of $20 \mathrm{mg} / \mathrm{kg}$ per os (p.o.) for 4 weeks $(n=8)$. In the $D+C$ group, administration of caffeine started 2 weeks after the streptozotocin injection. The non-diabetic and diabetic control rats (groups ND and D) were administered tap water (the vehicle) at the same volume of $2 \mathrm{ml} / \mathrm{kg}$ p.o. for 4 weeks. The caffeine dose was selected based on our previous study [36]. During the experiment, the body mass gain and blood glucose concentration were monitored [34, 35].

After 4 weeks of caffeine administration, the rats were fasted overnight. The animals were anesthetized with intraperitoneal injection of ketamine (Bioketan; Vetoquinol Biowet; $87.5 \mathrm{mg} / \mathrm{kg}$ ) and xylazine (Xylapan; Vetoquinol Biowet; $12.5 \mathrm{mg} /$ $\mathrm{kg}$ ), and killed by cardiac exsanguination. The serum was isolated from the blood for further assessments (protein content, SOD activity, CAT activity, AOPP concentration and MDA concentration). The lenses were collected, weighed and homogenized in PBS buffer, pH 7.4 (10\% v/w). Total homogenate was used for analysis of MDA concentration. For other studies, the homogenate was centrifuged at $10000^{*} \mathrm{~g}\left(15 \mathrm{~min},+4^{\circ} \mathrm{C}\right)$. In supernatant, the protein content, the activity of SOD, CAT, GPX and concentration of GSH and AOPP were determined. The biochemical parameters of oxidative stress were measured in a Tecan Infinite M200 PRO microplate reader with Magellan 7.2 software.

\section{Measurement of protein content}

The protein level in lenses and serum was determined by the biuret reaction using a Pointe Scientific kit.

\section{Estimation of oxidative stress biomarkers}

Activity of the enzymes SOD, CAT and GPX was tested with commercial kits (Cayman). GSH concentration analysis was carried out according to the method described by Sedlak and Lindsey, using Ellman's reagent [37, 38]. The AOPP assay was conducted based on the protocol described by Witko-Sarsat et al., with chloramine-T used as a reference and measured at $340 \mathrm{~nm}$ [39]. The test for MDA was carried out according to the method presented by Ohkawa et al. with 1,1,3,3-tetraethoxypropane used as a reference at $532 \mathrm{~nm}$ [40]. All necessary reagents were purchased from Sigma-Aldrich.

\section{Statistical analysis}

Results are presented as mean \pm SEM. Obtained results were statistically evaluated by one-way ANOVA followed by Fisher's LSD post-hoc test, or, in case of a lack of normality (Shapiro-Wilk test) or homogeneity of variance (Levene's test), by Krus-

Table I. Effect of caffeine on glucose level, body mass and lens mass of rats with streptozotocin (STZ)-induced diabetes

\begin{tabular}{|c|c|c|c|c|}
\hline Parameter & & ND & D & $D+C$ \\
\hline \multirow{3}{*}{$\begin{array}{l}\text { Non-fasting blood } \\
\text { glucose }[\mathrm{mg} / 100 \mathrm{ml}]\end{array}$} & Baseline & $117.3 \pm 4.2$ & $117.6 \pm 2.6$ & $109.4 \pm 2.2$ \\
\hline & $\begin{array}{l}\text { At the start of caffeine/ } \\
\text { vehicle administration }\end{array}$ & $101.6 \pm 3.3$ & $487.5 \pm 18.5^{000}$ & $529.9 \pm 12.4^{000}$ \\
\hline & At the end of the experiment ${ }^{\#}$ & $109.4 \pm 3.5$ & $571.1 \pm 18.4^{\circ 00}$ & $586.5 \pm 8.8^{\circ 00}$ \\
\hline \multirow[t]{3}{*}{ Body mass [g] } & Baseline & $195.2 \pm 4.6$ & $197.4 \pm 5.5$ & $192.0 \pm 4.6$ \\
\hline & $\begin{array}{l}\text { At the start of caffeine/ } \\
\text { vehicle administration }\end{array}$ & $205.0 \pm 5.0$ & $177.9 \pm 8.4^{\circ \circ}$ & $180.2 \pm 6.9^{\circ}$ \\
\hline & At the end of the experiment ${ }^{\#}$ & $219.3 \pm 4.6$ & $177.7 \pm 6.3^{\circ 00}$ & $177.6 \pm 6.8^{\circ 00}$ \\
\hline Lens mass [mg] & & $44.15 \pm 0.54$ & $41.16 \pm 0.56^{\circ 00}$ & $40.49 \pm 0.53^{000}$ \\
\hline \multicolumn{2}{|c|}{ Lens mass/body mass [mg/g] } & $0.202 \pm 0.004$ & $0.233 \pm 0.008^{\circ \circ}$ & $0.231 \pm 0.011^{\circ}$ \\
\hline
\end{tabular}

$N D$ - control, non-diabetic rats, $D$ - diabetic rats, $D+C$ - diabetic rats receiving caffeine $\left(20 \mathrm{mg} / \mathrm{kg}\right.$ p.o. for 4 weeks). ${ }^{*}$ The measurements of the body mass and blood glucose level were made before the last caffeine/vehicle administration. Results are presented as means \pm SEM $(n=7-9) .{ }^{\circ} p<0.05,{ }^{\circ 0} p<0.01,{ }^{\circ 00} p<0.001-$ statistically significantly different from the ND group. 
kal-Wallis ANOVA followed by the Mann-Whitney $U$ test, using Statistica 10 software (StatSoft, Tulsa, OK, USA).

\section{Results}

In the control diabetic rats, streptozotocin administration induced profound increases in the blood glucose levels. The body mass of those rats was significantly lower than that of the control non-diabetic rats, as it was previously reported [35]. Administration of caffeine to the diabetic rats, starting 2 weeks after the streptozotocin in jection, did not significantly affect the blood glucose concentration or the body mass in relation to the control diabetic rats (Table I).

Effect of caffeine on the lens mass and the lens mass/body mass ratio in diabetic rats

In the control diabetic rats, the mean mass of the lens was significantly lower $(p<0.001)$ and the lens mass/body mass ratio was markedly higher $(p<0.01)$ than in the non-diabetic animals. In the diabetic rats which received caffeine, the lens mass and the lens mass/body mass ratio were similar to that observed in the control diabetic rats (Table I).

\section{Effect of caffeine on the protein content} in the lens and serum of diabetic rats

In the control diabetic rats and the diabetic rats receiving caffeine, the protein content in the lens and the protein content in the serum were simi- lar to those observed in the non-diabetic animals (data not shown).

Effect of caffeine on the SOD activity in the lens and serum of diabetic rats

In comparison to the non-diabetic rats, the SOD activity in the lens of the diabetic rats was statistically significantly increased $(p<0.05)$, whereas the SOD activity in the serum was non-significantly increased. Administration of caffeine to the diabetic rats resulted in slight decreases of SOD activity in the lens and in the serum as compared to the control diabetic rats (Table II).

\section{Effect of caffeine on the CAT activity} in the lens and serum of diabetic rats

The CAT activity in the lens of the diabetic rats was higher than that in the non-diabetic rats; the difference was not statistically significant. In the diabetic rats, the CAT activity in the serum was strongly increased $(p<0.01)$ compared with the non-diabetic group. In the diabetic rats, after treatment with caffeine, decreases of the CAT activity (not statistically significant) in the lens and in the serum were observed compared to the control diabetic rats (Table II).

\section{Effect of caffeine on GPx activity in the lens of diabetic rats}

Activity of GPx in the lens was higher in the control diabetic rats than in the non-diabetic rats and administration of caffeine resulted in a de-

Table II. Effect of caffeine on oxidative stress parameters in the lens and serum of rats with streptozotocin-induced diabetes

\begin{tabular}{|c|c|c|c|}
\hline Parameter & ND & D & $D+C$ \\
\hline \multicolumn{4}{|l|}{ Lens: } \\
\hline SOD [U/mg protein] & $0.189 \pm 0.014$ & $0.230 \pm 0.009^{\circ}$ & $0.218 \pm 0.021$ \\
\hline CAT $[\mathrm{nmol} / \mathrm{min} / \mathrm{mg}$ protein] & $0.057 \pm 0.009$ & $0.068 \pm 0.009$ & $0.055 \pm 0.005$ \\
\hline GPx [nmol/min/mg protein] & $1.86 \pm 0.11$ & $2.21 \pm 0.11$ & $1.77 \pm 0.15$ \\
\hline $\mathrm{GSH}[\mu \mathrm{mol} / \mathrm{g}$ lens $]$ & $2.60 \pm 0.37$ & $1.39 \pm 0.24^{\circ}$ & $1.76 \pm 0.32$ \\
\hline AOPP [nmol/mg protein] & $3.43 \pm 0.39$ & $4.85 \pm 0.68$ & $4.31 \pm 0.43$ \\
\hline MDA [nmol/g lens] & $5.12 \pm 1.11$ & $11.8 \pm 2.07^{\circ \circ}$ & $3.94 \pm 0.71^{\star *}$ \\
\hline \multicolumn{4}{|l|}{ Serum: } \\
\hline SOD [U/mg protein] & $0.441 \pm 0.025$ & $0.568 \pm 0.057$ & $0.546 \pm 0.049$ \\
\hline CAT $[\mathrm{nmol} / \mathrm{min} / \mathrm{mg}$ protein] & $0.049 \pm 0.005$ & $0.082 \pm 0.007^{\circ \circ}$ & $0.069 \pm 0.011$ \\
\hline AOPP [nmol/mg protein] & $1.88 \pm 0.17$ & $3.00 \pm 0.43^{\circ \circ}$ & $2.42 \pm 0.50$ \\
\hline $\mathrm{MDA}[\mathrm{nmol} / \mathrm{ml}]$ & $3.54 \pm 0.31$ & $4.90 \pm 0.39^{\circ}$ & $3.02 \pm 0.38^{*}$ \\
\hline
\end{tabular}

$N D$ - control, non-diabetic rats, $D$ - diabetic rats, $D+C$ - diabetic rats receiving caffeine $(20 \mathrm{mg} / \mathrm{kg}$ p.o. for 4 weeks). Results are presented as means \pm SEM $(n=7-9) .{ }^{\circ} p<0.05,{ }^{\circ o} p<0.01$ - statistically significantly different from the ND group; ${ }^{*} p<0.05,{ }^{* *} p<0.01-$ statistically significant differences between the $D+C$ and the $D$ groups. 
crease of GPx activity compared with the control diabetic animals. The changes were not statistically significant (Table II).

\section{Effect of caffeine on GSH concentration in the lens of diabetic rats}

In the diabetic rats, the concentration of GSH in the lens was strongly reduced $(p<0.05)$ compared to the non-diabetic rats. Administration of caffeine to the diabetic rats resulted in an increase of the GSH concentration as compared to the diabetic control group (Table II).

\section{Effect of caffeine on AOPP concentration in the lens and serum of diabetic rats}

In the control diabetic rats, the AOPP concentration in the lens was non-significantly higher, and in the serum it was significantly higher $(p<$ $0.01)$ than in the non-diabetic rats. In comparison with the control diabetic rats, in the caffeine group, this parameter in the lens and in the serum was lowered (Table II).

\section{Effect of caffeine on MDA concentration in the lens and serum of diabetic rats}

The MDA concentrations in the lens and serum of the diabetic rats were significantly higher ( $p<0.01$ and $p<0.05$, respectively) than in the non-diabetic rats. After administration of caffeine to the diabetic rats, decreases of MDA concentrations in the lens and serum $(p<0.01$ and $p<0.05$, respectively), to the level of the healthy controls, were noted, compared to the control diabetic rats (Table II).

\section{Discussion}

Hyperglycemia, hypoinsulinemia, and body mass loss with simultaneous increase of food consumption are the symptoms of streptozotocin-induced diabetes in experimental animals [41-46]. The same symptoms are typical for patients with type 1 diabetes. Also, as in humans, the lenses of these animals are affected by cataract. Suryanarayana et al. [44] found that 30\% of rats with type 1 diabetes had subcapsular cataract and $60 \%$ of rats developed cortical cataract, which is characteristic for type 1 diabetes in humans. The other $10 \%$ of examined animals had an early stage of nuclear cataract. The presence of advanced cataracts in rats after administration of streptozotocin was confirmed by Saraswat et al. [47], Suryanarayana et al. [45], Gong et al. [42], Thiraphatthanavong et al. [46], and Bahmani et al. [41]. Many researchers have confirmed the changes of parameters of oxidative stress in the lens in the animal model of diabetes, thus indi- cating the role of ROS in the pathogenesis of lens opacity [42-45, 47].

The standard rat model of type 1 diabetes induced by single streptozotocin injection was used also in the present study. Streptozotocin caused damage to the pancreas and subsequently a disorder in insulin secretion, as evidenced by statistically significant increases in the blood glucose concentrations and decreases in the body mass. These observations are consistent with the literature [42-45].

In the present study, effects of caffeine on biomarkers of oxidative stress in the lens and in the serum of rats with streptozotocin-induced diabetes were assessed. Induction of diabetes in rats caused a reduction in the mass of the lens. Since the change in the lens mass of diabetic rats might have been due to a reduction of body mass in these animals, we calculated the lens mass/body mass ratio. The lens mass/body mass ratio of the diabetic rats was higher compared to the result of the non-diabetic rats. We suppose that the lens is less vulnerable to the catabolic influence of hyperglycemia than the whole body mass. The reason for the decrease in the lens mass was not protein impoverishment because the content of protein in the lens of the diabetic rats was the same as that in the non-diabetic rats. Likewise, we did not observe a change in the content of protein in the diabetic rat serum. The scope of our study does not give an opportunity to indicate the reason for the change in the lens mass.

Streptozotocin-induced diabetes increased SOD activity both in the rat lens and serum. Literature data indicate that the SOD activity in the lens in animals with streptozotocin-induced type 1 diabetes may increase $[41,43,45,48]$, decrease [42, 46,49 ] or remain unchanged [44]. Tas et al. [50] and Yildirimturk et al. [51] documented increases in the SOD activity in the serum of animals with streptozotocin-induced diabetes, whereas the decrease of the activity of this enzyme was described by Gao et al. [52]. The inconsistency regarding the SOD activity, as well as other oxidative stress biomarkers, in the literature may be the result of modifications of the methods such as different doses of streptozotocin or different time of assessment after the induction of diabetes.

In the present study, we observed higher CAT activity in the lens in the diabetic rats in comparison with the non-diabetic rats. This finding is in line with the literature data $[43,48]$. Also, in the present study, the serum CAT activity was higher in the diabetic rats. However, Kilari et al. [49] reported lower CAT activity of the diabetic rats.

Induction of diabetes by streptozotocin in rats caused an increase of GPx activity in the lens. As was the case for SOD and CAT, the literature data 
regarding the GPx activity in the lens are inconsistent. The researchers found both an increase [43-45] and a decrease [42, 46] of this enzyme in the lens of animals with streptozotocin-induced diabetes.

The GSH concentration in the diabetic rat lens was lower compared to the non-diabetic rats. The previous studies are consistent with our results [41, 43, 44, 49].

In the present study, the AOPP concentrations in the lens and serum of the diabetic rats were higher than in the non-diabetic rats. These observations are consistent with the literature $[43,51]$.

We demonstrated an increased concentration of MDA in the lens and serum of the diabetic rats in relation to the non-diabetic rats, which is in line with the literature data [42, 44, 46, 48, 50-52]. It should be mentioned that an increased concentration of MDA was also observed in patients with type 2 diabetes [53] and patients with cataract [54].

Yildirim et al. [55] in their study on patients with senile diabetic cataract observed an increase in the lens SOD, AOPP and MDA concentrations in comparison with the patients with senile non-diabetic cataract, which is consistent with our results.

According to the current knowledge, moderate caffeine intake by healthy adults at a dose level up to $400 \mathrm{mg} /$ day (equivalent to $5.3 \mathrm{mg} / \mathrm{kg}$ body mass/day in a $75-\mathrm{kg}$ person) is not associated with adverse effects [56]. In this study, caffeine was administered to the rats with streptozotocin-induced diabetes at a dose of $20 \mathrm{mg} / \mathrm{kg}$ p.o. for 4 weeks; such a dose in the rat diet was estimated as equivalent to approximately 2 cups of coffee daily in humans, due to the shorter caffeine plasma half-life in rats [57].

Caffeine administered to rats with streptozotocin-induced type 1 diabetes did not cause changes in blood glucose concentrations and did not affect the final body mass compared to control animals with diabetes. In the present study, caffeine did not change the lens mass and the lens mass/body mass ratio in animals with diabetes. Also, the lens and serum protein concentration in the diabetic rats treated with caffeine was similar to the results obtained in control rats with diabetes.

In contrast, there were favorable changes in oxidative stress parameters in the streptozotocin-induced diabetic rats after caffeine treatment. Changes of the oxidative stress biomarkers in the lens were similar to those observed in the serum, which may indicate the same mechanism of antioxidative action of caffeine in the whole organism.

Caffeine, as compared with control animals with diabetes, caused decreases in the SOD and CAT activity both in the lens and serum. Likewise, the GPx activity in the lens after administration of caffeine in diabetic rats was lower than in the control animals with diabetes.

So far, no research has been reported concerning the effect of caffeine on the SOD, CAT and GPx activity in the lens or in the serum in different animal models of diabetes mellitus or cataract. Barcelos et al. [58] observed a decrease of the SOD, CAT and GPx activity in the liver after administration of caffeine at a dose of $6 \mathrm{mg} / \mathrm{kg}$ for 4 weeks in rats subjected to swimming exercise training.

Administration of caffeine to diabetic rats increased the GSH concentration as compared with the control rats with diabetes. Varma et al. [28] induced cataracts by intraperitoneal injections of sodium selenite in neonatal rats. The pups were pretreated intraperitoneally with caffeine (5.15 $\mu \mathrm{mol})$, starting 2 days prior to the administration of selenite and continuing such treatment for next 21 days. Increased GSH concentrations were found in the lens, which was associated with a $36 \%$ reduction in opacity. In young rats with cataracts induced by a diet containing $24 \%$ galactose, lens GSH concentration was increased after application of eye drops with caffeine. At the same time, the researchers noted the inhibition of apoptosis and morphological changes in the lens [30]. The increase of GSH concentration in the lens after administration of caffeine is consistent with other studies in which various experimental models associated with oxidative stress were used in vivo or in vitro [12-15].

The AOPP concentration was lower in the lens and serum of the diabetic rats treated with caffeine than in the non-treated rats. There are no data in the literature to compare this result. However, the change is favorable, because the formation of AOPP in diabetes is induced by intensified oxidant-antioxidant imbalance, glycoxidation processes and coexisting inflammation [59].

In the present study, the MDA concentration after administration of caffeine to diabetic rats was lower both in the lens and serum, as compared with the control diabetic animals. This observation is consistent with that made in old rats (18-20 months), in which caffeine administered at $25 \mathrm{mg} / \mathrm{kg}$ for 6 weeks reduced the MDA concentration in the serum [11].

The study has some limitations. One of them is the number of oxidative stress parameters measured. It is supposed that diabetes can lead to cataract development, so another limitation of the study is that it did not include ophthalmic measurements.

The results of the present study may be of relevance in determining the effect of caffeine on the processes induced by ROS in vivo. Further, they can be an indication for clinical observations 
aiming to assess both preventive and therapeutic effects of caffeine in cataract.

\section{Acknowledgments}

This study was supported by the Medical University of Silesia in Katowice, Poland; Grant No. KNW-1-028/N/6/0.

We thank the staff and students of the Department of Pharmacology, School of Pharmacy with the Division of Laboratory Medicine in Sosnowiec for providing the biological material.

\section{Conflict of interest}

The authors declare no conflict of interest.

\section{References}

1. Sayin N, Kara N, Pekel G. Ocular complications of diabetes mellitus. World J Diabetes 2015; 6: 92-108.

2. Beebe DC, Holekamp NM, Shui YB. Oxidative damage and the prevention of age-related cataracts. Ophthalmic Res 2010; 44: 155-65.

3. Vinson JA. Oxidative stress in cataracts. Pathophysiology 2006; 13: 151-62.

4. Lou MF. Redox regulation in the lens. Prog Retin Eye Res 2003; 22: 657-82.

5. Maritim AC, Sanders RA, Watkins III JB. Diabetes, oxidative stress, and antioxidants: a review. J Biochem $\mathrm{Mol}$ Toxicol 2003; 17: 24-38.

6. Thiagarajan R, Manikandan R. Antioxidants and cataract. Free Radic Res 2013; 47: 337-45.

7. Ogawa H, Ueki N. Clinical importance of caffeine dependence and abuse. Psychiatry Clin Neurosci 2007; 61: 263-8.

8. Chattopadhyay D, Somaiah A, Raghunathan D, et al. Dichotomous effect of caffeine, curcumin, and naringenin on genomic DNA of normal and diabetic subjects. Scientifica (Cairo) 2014; 2014: 649261.

9. Nikitina D, Chen Z, Vallis K, et al. Relationship between caffeine and levels of DNA repair and oxidative stress in women with and without a BRCA1 mutation. J Nutrigenet Nutrigenomics 2015; 8: 174-84.

10. Varma SD, Kovtun S, Hegde KR. Role of ultraviolet irradiation and oxidative stress in cataract formation - medical prevention by nutritional antioxidants and metabolic agonists. Eye Contact Lens 2011; 37: 233-45.

11. El Agaty SM, Seif AA. Cardiovascular effects of longterm caffeine administration in aged rats. Ir J Med Sci 2015; 184: 265-72.

12. Varma SD, Hegde KR. Kynurenine-induced photo oxidative damage to lens in vitro: protective effect of caffeine. Mol Cell Biochem 2010; 340: 49-54.

13. Varma SD, Hegde KR. Prevention of oxidative damage to lens by caffeine. J Ocul Pharmacol Ther 2010; 26: 73-7.

14. Varma SD, Hegde KR, Kovtun S. Oxidative stress in lens in vivo: inhibitory effect of caffeine. A preliminary report. Mol Vis 2010; 16: 501-5.

15. Varma SD, Hegde KR, Kovtun S. UV-B-Induced damage to the lens in vitro: prevention by caffeine. J Ocul Pharmacol Ther 2008; 24: 439-44.

16. Devasagayam TPA, Kamat JP, Mohan H, et al. Caffeine as an antioxidant: inhibition of lipid peroxidation induced by reactive oxygen species. Biochim Biophys Acta 1996; 1282: 63-70.
17. Shi X, Dalal NS, Jain AC. Antioxidant behaviour of caffeine: efficient scavenging of hydroxyl radicals. Food Chem Toxicol 1991; 29: 1-6.

18. Abreu RV, Silva-Oliveira EM, Moraes MF, et al. Chronic coffee and caffeine ingestion effects on the cognitive function and antioxidant system of rat brains. Pharmacol Biochem Behav 2011; 99: 659-64.

19. Inkielewicz-Stepniak I, Czarnowski W. Oxidative stress parameters in rats exposed to fluoride and caffeine. Food Chem Toxicol 2010; 48: 1607-11.

20. McLellan TM, Caldwell JA, Lieberman HR. A review of caffeine's effects on cognitive, physical and occupational performance. Neurosci Biobehav Rev 2016; 71: 294-312.

21. Acheson KJ, Zahorska-Markiewicz B, Pittet P, et al. Caffeine and coffee: their influence on metabolic rate and substrate utilization in normal weight and obese individuals. Am J Clin Nutr 1980; 33: 989-97.

22. Bauer J, Maier K, Linderkamp O, et al. Effect of caffeine on oxygen consumption and metabolic rate in very low birth weight infants with idiopathic apnea. Pediatrics 2001; 107: 660-3.

23. Yeo SE, Jentjens RL, Wallis GA, et al. Caffeine increases exogenous carbohydrate oxidation during exercise. J Appl Physiol 2005; 99: 844-50.

24. Belza A, Toubro S, Astrup A. The effect of caffeine, green tea and tyrosine on thermogenesis and energy intake. Eur J Clin Nutr 2009; 63: 57-64.

25. Weinberg BA, Bealer BK. The world of caffeine: The science and culture of the world's most popular drug. $1^{\text {st }}$ ed. Routledge, New York 2001; 280.

26. Cappelletti S, Piacentino D, et al. Caffeine: cognitive and physical performance enhancer or psychoactive drug? Curr Neuropharmacol 2015; 13: 71-88.

27. Jiang $X$, Zhang D, Jiang W. Coffee and caffeine intake and incidence of type 2 diabetes mellitus: a meta-analysis of prospective studies. Eur J Nutr 2014; 53: 25-38.

28. Varma SD, Hegde KR, Kovtun S. Inhibition of selenite-induced cataract by caffeine. Acta Ophthalmol 2010; 88: e245-49.

29. Varma SD, Kovtun S. Protective effect of caffeine against high sugar-induced transcription of microRNAs and consequent gene silencing: a study using lenses of galactosemic mice. Mol Vis 2013; 19: 493-500.

30. Varma SD, Kovtun S, Hegde K. Effectiveness of topical caffeine in cataract prevention: studies with galactose cataract. Mol Vis 2010; 16: 2626-33.

31. Varma SD, Kovtun S, Hegde KR. Role of ultraviolet irradiation and oxidative stress in cataract formation-medical prevention by nutritional antioxidants and metabolic agonists. Eye Contact Lens 2011; 37: 233-45.

32. Szkudelski T. The mechanism of alloxan and streptozotocin action in $b$ cells of the rat pancreas. Physiol Res 2001; 50: 536-46.

33. Yümün G, Kahaman C, Kahaman N, et al. Effects of hyperbaric oxygen therapy combined with platelet-rich plasma on diabetic wounds: an experimental rat model. Arch Med Sci 2016; 12: 1370-6.

34. Folwarczna J, Janas A, Cegieła U, et al. Caffeine at moderate dose did not affect the skeletal system of rats with streptozotocin-induced metabolic disorders. Bone Abstracts (2016) 5 P274. DOI:10.1530/boneabs.5.P274.

35. Folwarczna J, Janas A, Pytlik M, et al. Effects of trigonelline, an alkaloid present in coffee, on diabetes-induced disorders in the rat skeletal system. Nutrients 2016; 8: 133. 
36. Folwarczna J, Pytlik M, Zych $M$, et al. Favorable effect of moderate dose caffeine on the skeletal system in ovariectomized rats. Mol Nutr Food Res 2013; 57: 1772-84.

37. Ellman GL. Tissue sulfhydryl groups. Arch Biochem Biophys 1959; 82: 70-7.

38. Sedlak J, Lindsay RH. Estimation of total, protein-bound and nonprotein sulfhydryl groups in tissue with Ellman's reagent. Anal Biochem 1968; 25: 192-205.

39. Witko-Sarsat V, Friedlander $M$, Capeillère-Blandin C et al. Advanced oxidation protein products as a novel marker of oxidative stress in uremia. Kidney Int 1996; 49: 1304-13.

40. Ohkawa H, Ohishi N, Yagi K. Assay for lipid peroxides in animal tissues by thiobarbituric acid reaction. Anal Biochem 1979; 95: 351-8.

41. Bahmani F, Bathaie SZ, Aldavood SJ, et al. Glycine therapy inhibits the progression of cataract in streptozotocin-induced diabetic rats. Mol Vis 2012; 18: 439-48.

42. Gong X, Zhang Q, Tan S. Inhibitory effect of r-hirudin variant III on streptozotocin-induced diabetic cataracts in rats. Sci World J 2013; 2013: 630651.

43. Wojnar W, Kaczmarczyk-Sedlak I, Zych M. Diosmin ameliorates the effects of oxidative stress in lenses of streptozotocin-induced type 1 diabetic rats. Pharmacol Rep 2017; 69: 995-1000.

44. Suryanarayana P, Saraswat M, Mrudula T, et al. Curcumin and turmeric delay streptozotocin-induced diabetic cataract in rats. Invest Ophthalmol Vis Sci 2005; 46: 2092-99.

45. Suryanarayana P, Saraswat M, Petrash JM, et al. Emblica officinalis and its enriched tannoids delay streptozotocin induced diabetic cataract in rats. Mol Vis 2007; 13: 1291-7.

46. Thiraphatthanavong P, Wattanathorn J, Muchimapura $S$, et al. The combined extract of purple waxy corn and ginger prevents cataractogenesis and retinopathy in streptozotocin-diabetic rats. Oxid Med Cell Longev 2014; 2014: 789406.

47. Saraswat M, Suryanarayana P, Reddy PY, et al. Antiglycating potential of Zingiber officinalis and delay of diabetic cataract in rats. Mol Vis 2010; 16: 1525-37.

48. Patil MA, Suryanarayana P, Putcha UK, et al. Evaluation of neonatal streptozotocin induced diabetic rat model for the development of cataract. Oxid Med Cell Longev 2014; 2014: 463264.

49. Kilari EK, Putta S. Delayed progression of diabetic cataractogenesis and retinopathy by Litchi chinensis in STZ-induced diabetic rats. Cutan Ocul Toxicol 2017; 36: 52-9.

50. Tas S, Sarandöl E, Dirican M. Vitamin B6 supplementation improves oxidative stress and enhances serum paraoxonase/arylesterase activities in streptozotocin-induced diabetic rats. Sci World J 2014; 2014: 351598.

51. Yildirimturk S, Batu S, Alatli C, et al. The effects of supplemental melatonin administration on the healing of bone defects in streptozotocin-induced diabetic rats. J Appl Oral Sci 2016; 24: 239-49.

52. Gao J, Han YL, Jin YL, et al. Protective effect of polysaccharides from Opuntia dillenii Haw. fruits on streptozotocin-induced diabetic rats. Carbohydr Polym 2015; 124: 25-34.

53. Ahmed FN, Naqvi FN, Shafiq F. Lipid peroxidation and serum antioxidant enzymes in patients with type $2 \mathrm{di}$ abetes mellitus. Ann N Y Acad Sci 2006; 1084: 481-89.

54. Kaur J, Kukreja S, Kaur A, et al. The oxidative stress in cataract patients. Clin Diagn Res 2012; 6: 1629-32.
55. Yildirim Z, Yildirim F, Ucgun NI, et al. The evaluation of the oxidative stress parameters in nondiabetic and diabetic senile cataract patients. Biol Trace Elem Res 2009; 128: 135-43.

56. Doepker C, Lieberman HR, Smith AP, et al. Caffeine: friend or foe? Annu Rev Food Sci Technol 2016; 7: 117-37.

57. Ohta M, Cheuk G, Thomas KA, et al. Effects of caffeine on the bones of aged, ovariectomized rats. Ann Nutr Metab 1999; 43: 52-9.

58. Barcelos RP, Souza MA, Amaral GP, et al. Caffeine supplementation modulates oxidative stress markers in the liver of trained rats. Life Sci 2014; 96: 40-5.

59. Kalousova M, Skrha J, Zima T. Advanced glycation end-products and advanced oxidation protein products in patients with diabetes mellitus. Physiol Res 2002; 51: 597-604. 